\title{
Experimental Investigation and Mathematical Modelling of Pressure Transfer Function for Air Compressor
}

\author{
Mishaal A. AbdulKareem \\ College of Engineering, Al-Mustansiriyah University, \\ Al-Bab AL-Muatham, P.O. Box 46049, Baghdad, 10047, Iraq \\ *Corresponding Author E-mail: dr.mishaal@uomustansiriyah.edu.iq
}

\begin{abstract}
A mathematical model is developed to estimate the pressure response of an insulated electric air compressor. A pressure switch is modeled as a comparator and the electric motor as an amplifier. It is assumed that the compressed air is a perfect gas when applying the isentropic process. In addition, the effect of a step, ramp and sinusoidal functions of disturbance signals on the air pressure has been studied. A good agreement was obtained when comparing the predicted results with the measured values obtained from the experimental test that was done using a $(1.32 \mathrm{~kW}, 23$ litter and 8 bar) electric reciprocating air compressor. In addition, the same behavior of the predicted results was obtained when compared with results of a previously published article. It was found that the time constant of this control system is directly proportional with the value of the spring constant that is inserted inside the pressure switch and with the volume of air storage vessel, and it is inversely proportional with the gain of the amplifier and with the effective cross-sectional area of the pressure switch diaphragm and it is independent of the value of operating pressure set point. In addition, when the value of disturbance signal is positive, it will increase the output pressure response and when it is negative, it will decrease it.
\end{abstract}

Keywords: Integral controller; pressure response; air compressor; step function disturbance; ramp disturbance; sinusoidal disturbance.

\section{Introduction}

Compressors are devices that are most commonly used in industrial, domestic applications, petrochemical plants and oil refineries. It compresses air, hydrogen, R12 or any other gas. Air compressors contributes in many applications such as operating pneumatic tools in workshops and many industrial production lines including automobiles, food, paper, drug industries, metallurgy, chemical, tobacco, machinery, and it is commonly driven by an electric motor or steam turbine as in petrochemical plants and oil refineries.

(Zhao, 1992) presented a mathematical model for the dynamic analysis of a vertical reheat boiler and the application of this model to the optimal design of a drum water level controller. A numerical Finite Difference Technique was developed to formulate this model. Results showed that an incremental PID controller plus adapt feedforward compensator can be successfully employed for the control of water level in boiler drums.

There are many disturbance factors in boilers operation and it is hardly to control the main steam pressure. The advantages of the Fuzzy Control and the PID control are integrated to design the fuzzy-PI controller by combining the SIMULINK and FUZZY tool box organically. The simulation results show that this control method greatly enhances the control effect of the nonlinear, hysteresis system, and improves the system's flexibility and adaptability (Panxiang et. al., 2011).

The characteristics of steam pressure-controlled object is analyzed using a fuzzy adaptive PID control based on the cascade control system. (Zhou et. al., 2012) constructed a mathematical model using MATLAB simulation to compare the fuzzy adaptive PID cascade control with conventional PID control. The results prove that the former has a good control effect.

(Sniders and Komass, 2012) developed a mathematical modeling and simulation in MATLAB SIMULINK environment to consider the possibility of steam production and supply process improvement by perfection of the steam boiler control system, applying invariance principle that makes possible preemptive compensation of the influence of steam expenditure as a disturbance on the control process quality and efficiency. The control unit was low pressure steam boiler with one input impact to control - the heat flow of burning gas mixture fuel, one measured output parameter of the process - the steam pressure, and the main disturbance as a load impact - the steam expenditure. The mathematical and virtual models and blockdiagrams for transient process simulation was compiled, allowing to start practical design and investigation of steam boiler invariant control system with high operation stability under essentially fluctuating load. The simulation results proved that the optimal solution for the transient process improvement in steam boiler, taking in account fluctuating load, was invariant PID-DPC two loop control system with disturbance impact on steam pressure preemptive compensation. Under invariant control the steam pressure overshoots decrease substantially in comparison with the traditional PID-feedback control method.

(Chukanova et. al., 2013) Developed a mathematical model to study the screw compressor behavior that is connected to a close loop system and operating under unsteady conditions during; startup, and variation of compressor shaft speed, tank volume, tank pressure and throttle valve position. This mathematical model was based on the differential equations of conservation of mass and energy. The first start-up condition begins from atmospheric pressure at the compressor discharge. 
A good agreement was observed when the predicted results was compared with those obtained from experimental tests that was done using an oil-flooded twin screw compressor that is driven by six belts coupled to $75 \mathrm{kw}$ electric motor.

(Nia and shabaninia, 2014) presented a robust scheme of a multivariable non-linear process for controlling the pressure of gas collectors of a coke oven. The effectiveness of the traditional PI (Proportional Integral) control for controlling gas collector pressure of the coke oven is difficult to be perfect. A hybrid control scheme based on fuzzy PI and conventional PI methods (called fuzzy PI-PI) is presented. Based on the application of the fuzzy PI-PI and type-2 fuzzy PI-PI control approaches, a highperformance pressure control has been obtained. A comparative study between the conventional PI, fuzzy PI-PI and Type-2 fuzzy PI-PI control paradigms has been carried out. The comparison shows that the Type-2 fuzzy PI outperforms its rival.

(Ponce et. al., 2016) designed and evaluated a dynamic simulator for an ISCC (Integrated solar combined cycle) plant. The simulator is based on proportional-integral controllers and was developed in the MATLAB/Simulink ${ }^{\circledR}$ environment. A control strategy was presented. The intent of the strategy was to regulate the steam pressure of the superheater of the ISCC plant. The combined use of the simulator and the control strategy allows for the quantification of the reduction in fuel consumption that can be achieved when integrated solar collectors were used in a combined cycle plant. It was found that the ISCC plant simulator is suitable for designing, evaluating and testing control strategies and for planning the integration of solar and combined cycle plants.

(Chang et. al., 2017) developed a mathematical model to analyze the transient response of the high-pressure steam pipeline network in a refinery. A sequentially iterative fully implicit method has been used to solve the unsteady nonlinear equations in a pipeline. The proposed method was then combined with the modified Hardy-Cross method to study the transient response in a looped pipeline network. A complex high-pressure steam network problem was used for demonstrating the applicability of the proposed solution method in analyzing the transient response in a pipeline network. This analysis was critical for optimizing operation and control of the steam distribution systems.

(PAN, 2017) Designed a hardware and software system of a gearshift integral PID controller for air compressor pressure control system using a kernel that is made of a single chip microcomputer PIC16F877. It was found that the application of this system showed many advantages.

In this paper, a mathematical model will be developed to estimate the pressure response of a perfectly insulated electric air compressor. A commercial, diaphragm type pressure switch device will be used in this pressure integral control system to act as a comparator and the electric motor will be modeled as a signal amplifier. The block diagram of this pressure integral control system will be developed assuming that the compressed air is a perfect gas when applying the isentropic air compression process. In addition, the effect of a step, ramp and sinusoidal functions of disturbance signals on the air compressor pressure response will be studied. The predicted results of the mathematical model will be compared with the measured values from the experimental test using a $(1.32 \mathrm{~kW})$ electric reciprocating air compressor with a storage vessel volume of (23 litter) and maximum operating pressure of $(8 \mathrm{bar})$ and using a diaphragm type pressure switch device of a low range of pressure set point up to (7.5 bar). Also, it will be compared with results of a previously published article.

\section{Mathematical Model}

Consider an electric air compressor that is equipped with a pressure switch device to control and maintain the desired output pressure value $\left(P_{o}\right)$ during air compressor operation. At $(t=0)$, the pressure set point on the pressure switch device is suddenly changed to a unit step value of $\left(P_{\text {in }}\right)$, and the air inlet temperature to the compressor is $\left(T_{i n}\right)$, as shown in Fig. 1. It is required to predict the air compressor pressure response during its operation. To solve this problem, the following assumptions are considered:

1. The electric air compressor is perfectly insulated.

2. Isentropic air compression ideal process.

3. The compressed air is assumed to be a perfect gas.

4. The diaphragm type pressure switch device is a low range pressure set point up to $(7.5 \mathrm{bar})$.

In order to predict the pressure response of the air compressor system during air compression, the transfer function of each component of the pressure control system has to be estimated. Then, these transfer functions of all system components will be assembled to give the required transfer function of the air compressor pressure control system (Raven, 1995) and (Ogata, 2010).

\subsection{Comparator}

Applying Hooke's Law on the pressure switch device that is modeled as a comparator. Hence, the relation between the input signal $\left(P_{\text {in }}\right)$, the feedback signal $\left(P_{o}\right)$ and the output signal $(x)$ is estimated as follows;

$\sum F=K_{s} x$

$\left(P_{\text {in }}-P_{o}\right) A_{d}=K_{s} x$

$\therefore x=\frac{A_{d}}{K_{s}}\left(P_{\text {in }}-P_{o}\right)$

The transfer function of this relation is shown in Fig. 2, (Raven, 1995) and (Ogata, 2010).

\subsection{Amplifier}

When the diaphragm of the pressure switch senses the difference in pressure between both of its sides. It compresses the spring and moves it a distance $(x)$ in the direction of the low-pressure side. The micro switch, that is mounted inside the pressure switch, will activate the electric motor.

Hence, the electric motor is modeled as a signal amplifier and the relation between the spring displacement $(x)$ and the power of the electric motor $\left(W_{M}^{*}\right)$ is modeled as:

$W_{M}^{*}=K_{c} x$

Therefore, the transfer function of the signal amplifier is shown in Fig. 3, (Raven, 1995) and (Ogata, 2010).

\subsection{Hydraulic Process}

The hydraulic process is modeled as follows, (Klein and Nellis, 2011) and (Cengel and Boles, 2015):

$W_{M}^{*}=m w_{M}^{*}$

$w_{M}^{*}=w_{a}^{*}+q_{I_{i} \Omega s s}^{*}$

Since the air compressor is perfectly insulated and neglect the mechanical losses. Hence,

$q_{\text {Loss }}^{*} \approx 0$ 
$w_{M}^{*}=w_{a}^{*}$

Therefore, the transfer function of these relations is shown in Fig. 4, (Raven, 1995) and (Ogata, 2010).

$w_{a}^{*}=\frac{d w_{a}}{d t}=D w_{a}$

Hence, the transfer function of the integral controller for this control system is shown in Fig. 5, (Raven, 1995) and (Ogata, 2010). The Specific hydraulic power supplied to the compressor is estimated as, (Klein and Nellis, 2011) and (Cengel and Boles, 2015):

$w_{a}=c_{p_{a}}\left(T_{o}-T_{i n}\right)$

The effect of the disturbance signal is added to the above relations and it can be modeled, (Klein and Nellis, 2011) and (Cengel and Boles, 2015), as shown in Fig. 6. The isentropic air compression ideal process gives:

$\frac{T_{o}}{T_{i n}}=\left(\frac{P_{o}}{P_{i n}}\right)^{\frac{K-1}{K}} \Rightarrow T_{o}=T_{i n}\left(\frac{P_{o}}{P_{i n}}\right)^{\frac{K-1}{K}}$

Since the compressed air is assumed as perfect gas and it will follow the perfect gas law and the air density $(\rho)$ is estimated as follows, (Klein and Nellis, 2011) and (Cengel and Boles, 2015):

$P_{o}=\rho R T_{o} \quad \Rightarrow \quad \rho=\frac{P_{o}}{R T_{o}}$

Therefore, the transfer function of the perfect gas law is shown in Fig. 7, (Raven, 1995) and (Ogata, 2010).

\subsection{Assembly of Block Diagram for all process components}

The block diagram of all process components is obtained from the assembly of all the block diagrams, that are shown in Fig. 2 to 7 , as shown in Fig. 8.

\subsection{Reduction of Assembled Block Diagram}

Simplify and rearrange the assembled block diagram in Fig. 8, yields the final block diagram in Fig. 9. The output signal $\left(P_{o}\right)$ can be estimated from the transfer function that is predicted from Fig. 9, as follows, (Raven, 1995) and (Ogata, 2010):

$P_{o}=\frac{1}{1+\tau D}\left(P_{i n}+\rho R T_{\text {in }}\right)$

Eq. (8) represent the general transfer function of the air compressor pressure control system. The time constant of the pressure control system is, (Raven, 1995) and (Ogata, 2010):

$\tau=\frac{K_{s} m c_{p a}}{A_{d} K_{c} \rho R}=\frac{K_{s} V_{a}}{A_{d} K_{c}} \frac{K}{(K-1)}$

\subsubsection{Pressure Response with no Change in $\left(T_{\text {in }}\right)$}

If $\left(P_{\text {in }}=\Delta P_{\text {in }}=\right.$ Constant $),\left(T_{\text {in }}=0\right)$ and all initial conditions=0. Hence, Eq. (8) is reduced as follows, (Raven, 1995) and (Ogata, 2010):
$P_{o}=\frac{1}{1+\tau D} \Delta P_{i n}$

Using the Laplace transformation, (Raven, 1995) and (Ogata, 2010) to solve Eq. (10), as follows;

$\mathcal{L} P_{o}(t)=\mathcal{L}\left\{\frac{1}{1+\tau D} \Delta P_{\text {in }}(t)\right\}$

$P_{o}(s)=\Delta P_{\text {in }}\left\lceil\frac{1}{s}-\frac{1}{s+\frac{1}{\tau}}\right\rceil$

Taking $\left(\mathcal{L}^{-1}\right)$ for Eq. (11), yields;

$P_{o}(t)=\Delta P_{\text {in }}\left[1-e^{-\left(\frac{t}{\tau}\right)}\right]$

Eq. (12) represent the general transfer function of pressure response when no disturbance signal is present, $\left(T_{\text {in }}=0\right)$.

\subsubsection{Pressure Response with no Change in $\left(P_{\text {in }}\right)$}

If $\left(T_{\text {in }}=\Delta T_{\text {in }}=\right.$ Constant $),\left(P_{\text {in }}=0\right)$ and all initial conditions $=0$. Hence, Eq. (8) is reduced as follows, (Raven, 1995) and (Ogata, 2010):

$P_{o}=\frac{\rho R}{1+\tau D} \Delta T_{i n}$

Using the Laplace transformation, (Raven, 1995) and (Ogata, 2010) to solve Eq. (13), as follows;

$\mathcal{L} P_{o}(t)=\mathcal{L}\left\{\frac{1}{1+\tau D} \rho R \Delta T_{\text {in }}(t)\right\}$

$P_{o}(s)=\rho R \Delta T_{\text {in }}\left\lceil\frac{1}{s}-\frac{1}{s+\frac{1}{\tau}}\right\rceil$

Taking $\left(\mathcal{L}^{-1}\right)$ for Eq. (14), yields;

$P_{o}(t)=\rho R \Delta T_{\text {in }}\left[1-e^{-\left(\frac{t}{\tau}\right)}\right]$

Eq. (15) represent the general transfer function of pressure response when no input signal is present, $\left(P_{\text {in }}=0\right)$, (Raven, 1995) and (Ogata, 2010). Combining Eq. (12) and (15) then simplifying will give the following;

$P_{o}(t)=\left(\Delta P_{\text {in }}+\rho R \Delta T_{\text {in }}\right)\left[1-e^{-\left(\frac{t}{\tau}\right)}\right]$

Eq. (16) represent the general transfer function of air compressor pressure response.

\section{Experimental Setup}

A $(1.32 \mathrm{~kW})$ electric reciprocating air compressor with insulated storage vessel of (23 litter) and maximum operating pressure of ( 8 bar) is used during the experimental test as shown in Fig. 10-a. It is equipped with a (13 $\mathrm{mm}$ diameter) diaphragm type pressure switch device of a low range of pressure set point up to (7.5 bar). that is shown in Fig. 10-b, which is used in this pressure control system to control and maintain the desired output pressure $\left(P_{o}\right)$ and to act as a comparator. The atmospheric air temperature 
is measured using a $\left(-10\right.$ to $\left.200^{\circ} \mathrm{C}\right)$ thermometer and the output air pressure is measured using a $(0$ to 6 bar $)$ Bourdon gauge. In addition, the electric current and voltage that is operating the electric motor were measured using a DT266 clamp meter. Finally, the time was recorded using a digital stop watch. The power supplied to the electric motor is estimated using the measured values of electric current and voltage as follows, (Klein and Nellis, 2011) and (Cengel and Boles, 2015):

$W_{M}^{*}=A \cdot V$

\section{Calibration and Error Analysis}

The BUDENBERG dead weight tester was used to calibrate the Bourdon gauge and predict the percentage error for pressure measurements. Table (1) shows the results of the error analysis. It's clear that the maximum error of measuring pressure is $(16.04 \%)$

\section{Results and Discussion}

A mathematical model has been developed to estimate the pressure response of a perfectly insulated electric air compressor. A commercial pressure switch was used in this pressure integral control system to act as a comparator and the electric motor was modeled as a signal amplifier. This model assume that the compressed air is a perfect gas when applying the isentropic process. In addition, the effect of a step, ramp and sinusoidal functions of disturbance signals on the air compressor pressure response has been studied. To estimate the spring constant $\left(K_{S}\right)$, a set of data for the values of the spring displacement $(x)$ and the corresponding values of acting force $(F)$ on the spring are plotted as shown in Fig. 11. The spring constant value is $\left(10.605 \frac{\mathrm{kN}}{\mathrm{m}}\right)$ and it equals the slope of the line that was estimated using the data best linear fit.

\subsection{Validation of Results}

To validate the predicted results, an experimental test was done. Initially, at $(t=0)$, the desired pressure $\left(P_{\text {in }}\right)$ on the pressure switch device was set to $(2 \mathrm{bar})$ and the atmospheric air temperature and pressure are $\left(21.3^{\circ} \mathrm{C}\right)$ and $(1.0$ bar abs. $)$ respectively. At $(t>0)$, a list of measured values of the time, the output air pressure $\left(P_{o}\right)$, the electric current $(A)$ and voltage $(V)$ were recorded respectively. When the output pressure $\left(P_{o}\right)$ equals the pressure set point $\left(P_{i n}\right)$, the pressure switch will cut off the electric power to stop the motor. A good agreement was obtained when comparing the predicted results of the mathematical model with the measured values obtained from the experimental test as shown in Fig. 12-a. The same behavior of the air compressor pressure response is illustrated in Fig. 12-b, (Chukanova et. al., 2013)

\subsection{Pressure Response with No Disturbance Signal}

Fig. 13-a shows the change in air compressor pressure response when altering the volume of the compressed air storage vessel. It is clear that when increasing the volume of the compressed air storage vessel, it will increase the value of time constant of the control system, Eq. (9), leading to a slower pressure response. The same behavior of the steam pressure response is illustrated in Fig. 13-b when altering the volume of the compressed air storage vessel ( Chukanova et. al., 2013)

Fig. 14 shows the change in air compressor pressure response when altering the rated power of the electrical motor. It is clear that when increasing the rated power of the electric motor, it will increase the gain of the amplifier $\left(K_{c}\right)$. Therefore, it will reduce the value of time constant of the control system, Eq. (9), leading to a faster pressure response.

Fig. 15 shows the change in air compressor pressure response when altering the values of diaphragm diameter. It is clear that when increasing the value of diaphragm diameter, it will increase the affective cross-sectional area of diaphragm $\left(A_{d}\right)$. Therefore, it will reduce the value of time constant of the control system, Eq. (9), leading to a faster pressure response.

Fig. 16 shows the change in air compressor pressure response when altering the values of spring constant. It is clear that when increasing the values of spring constant, it will increase the value of time constant of the control system, Eq. (9), leading to a slower pressure response.

Fig. 17 shows the change in air compressor pressure response when altering the values of input pressure signal. It is clear that when increasing the value of input pressure signal, it will increase the value of output pressure, Eq. (12). In addition, Fig. 17 shows that the time constant of this control system is independent of the value of the input pressure set point.

\subsection{Pressure response with disturbance signal}

Fig. 18 shows the change in air compressor pressure response when altering different types of positive and negative functions of disturbance signals (step, ramp and sinusoidal functions). It is clear that when the value of a disturbance signal is positive, it will be added to the input pressure signal leading to an increase in the output pressure response and when it is negative, it will be subtracted from the input pressure signal leading to a decrease in the output pressure response, as shown in Eq. (9), Eq. (15).

\section{Conclusions}

The mathematical model of pressure response of a perfectly insulated electric air compressor has been estimated using the block diagram method. A commercial, diaphragm type pressure switch device was modeled to act as a comparator and the electric motor was modeled as a signal amplifier. This mathematical model assume that the compressed air is a perfect gas when applying the isentropic air compression ideal process. In addition, the effect of a step, ramp and sinusoidal functions of disturbance signals on the air compressor pressure response has been investigated. In general, it was found that the time constant of the pressure integral control system is directly proportional with the value of the spring constant that is inserted inside the pressure switch device and with the volume of the compressed air storage vessel, and it is inversely proportional with the gain of the amplifier (the electric power of the motor) and with the effective cross-sectional area of the diaphragm that is inserted inside the pressure switch device. Also, it was found that the time constant is independent of the value of operating pressure set point. In addition, it was found that when the value of disturbance signal is positive, it will be added to the input pressure signal leading to an increase in the output pressure response and when it is negative, it will be subtracted from the input pressure signal leading to a decrease in the output pressure response. Hence, the developed mathematical model is recommended to predict the pressure response for commercial electric air compressors operating under step, ramp and sinusoidal functions of disturbance signals. 


\section{Acknowledgements}

The author would like to thank his wife for her patience and unlimited support. Without her, this paper could not be done.

\section{References}

[1] Ali Reza Jamshid Nia, F. S. (2014) 'Intelligent Control for Gas Collector Pressure of Coke Oven', International Journal of Engineering and Technology Research, 2(1), pp. 1-14.

[2] Andris Sniders and Toms Komass (2012) 'Invariant Method of Load Independent Pressure Control in Steam Boiler', Electrical, Control and Communication Engineering Journal, Faculty of Engineering, Latvia University of Agriculture, pp. 5-10.

[3] Carolina V. Ponce, Doris Saez, Carlos Bordons, Alfredo Núnez (2016) 'Dynamic simulator and model predictive control of an integrated solar combined cycle plant', Energy, 109(August), pp. 974-986. doi: 10.1016/j.energy.2016.04.129.

[4] Chiao-Ying Chang, Shih-Han Wang, Yu-Cheng Huang, Cheng Liang Chen (2017) 'Transient Response Analysis of High Pressure Steam Distribution Networks in A Refinery', in 6th International Symposium on Advanced Control of Industrial Processes (AdCONIP). aipei, Taiwan: IEEE, pp. 418-423.

[5] Chunyue PAN (2017) 'Air Compressor Pressure Control System Based On Gearshift Integral PID Controller', MATEC Web of Conferences, $139, \quad$ p. 00199 . doi 10.1051/matecconf/201713900199.

[6] Ekaterina Chukanova, Nikola Stosic, Ahmed Kovacevic (2013) 'Experimental Investigation and Numerical Modelling of Dynamic Behaviour of Screw Compressor Plant', Universal Journal of Engineering Science, 1(3), pp. 68-79. doi: 10.13189/ujes.2013.010302.

[7] Francis H. Raven (1995) Automatic Control Engineering. 5th ed. New Delhi: McGraw-Hill.

[8] Jian Zhao (1992) Simulation of Boiler Drum Process Dynamics and Control. McGill University, Montreal, Canada.

[9] Katsuhiko Ogata (2010) Modern Control Engineering. 5th ed. New Jersey: Pearson Education, Inc., publishing as Prentice Hall.

[10] Rong Panxiang, Han Leng, Li Chao (2011) 'Research on the main steam pressure control system of boilers based on fuzzy PI control', Proceedings of the 6th International Forum on Strategic Technology, IFOST 2011, 2, pp. 927-930. doi: 10.1109/IFOST.2011.6021172.

[11] Sanford Klein, Gregory Nellis (2011) Thermodynamics. doi: 10.1017/CBO9780511994883.

[12] Yiheng Zhou, Longyue Yang, Hailin Pu, Ziyu Zhao, Fei Liu, Zheng Chen (2012) 'Boiler Steam Pressure Control System Based on Fuzzy Control', Advanced Materials Research, 462, pp. 732-737. doi: 10.4028/www.scientific.net/AMR.462.732.

[13] Yunis A. Cengel, Michael A. Boles (2015) THERMODYNAMICS: AN ENGINEERING APPROACH. 8th edn. Mc Graw-Hill Education

\section{Nomenclature}

$A=$ Electric current supplied to the electric motor, (Ampere)

$A_{d}=$ Affective cross-sectional area of diaphragm, $\left(\mathrm{m}^{2}\right)$

$c_{p_{a}}=$ Specific heat capacity of compressed air, $\left(\frac{j}{k g \cdot K}\right)$

$F=$ Force acting on the spring, $(N)$

$K=1.4$, index of isentropic air compression ideal process.

$K_{C}=$ Gain (Amplifier constant), $\left(\frac{W}{m}\right)$

$K_{S}=$ Spring constant $\left(\frac{N}{m}\right)$

$m$ = Mass of compressed air in the storage vessel, $(\mathrm{kg})$

$P_{i n}=$ Input pressure, $\left(\right.$ set point value on pressure switch), $\left(\frac{N}{m^{2}}\right)$

$P_{o}=$ output pressure, (actual measured value of pressure), $\left(\frac{N}{m^{2}}\right)$

$q_{\text {Loss }}^{*}=$ Specific mechanical losses and heat losses to surrounding, $(W / k g)$

$R=287$, Specific gas constant, $\left(\frac{j}{k g \cdot K}\right)$

$T_{\text {in }}=$ Disturbance value of temperature change (step, ramp and sinusoidal function), Eq. (9), (K)

$T_{\text {in }}=$ Inlet air temperature, Eq. (7), $(K)$

$T_{o}=$ Outlet air temperature, $(K)$

$V_{a}=$ Volume of the compressed air storage vessel, $\left(\mathrm{m}^{3}\right)$

$V=$ Electric voltage supplied on the terminals of the electric motor, (volt)

$w_{a}^{*}=$ Specific hydraulic power supplied to the compressor, $(W / \mathrm{kg})$

$w_{M}^{*}=$ Specific power supplied to the electric motor, $(\mathrm{W} / \mathrm{kg})$

$W_{M}^{*}=$ Power supplied to the electric motor, $(W)$

$X=$ displacement of spring, $(m)$

\section{Greek Symbols}

$\tau=$ Time constant of the pressure control system, $(\mathrm{sec})$

$\rho=$ Air density, $\left(\frac{\mathrm{kg}}{\mathrm{m}^{3}}\right)$

Table 1: Calibration and error analysis of Bourdon gauge

\begin{tabular}{|c|c|c|c|c|c|c|c|}
\hline \multirow{2}{*}{$\begin{array}{l}\text { Actual pressure } \\
\text { (bar) }\end{array}$} & \multicolumn{3}{|c|}{ Pressure readings, (bar) } & \multicolumn{3}{|c|}{ Correction (bar) } & \multirow{2}{*}{$\begin{array}{l}\text { Error } \\
(\%)\end{array}$} \\
\hline & Weight increase & $\begin{array}{l}\text { Weight } \\
\text { decrease }\end{array}$ & Average & Weight increase & $\begin{array}{l}\text { Weight } \\
\text { decrease }\end{array}$ & Average & \\
\hline 1.18 & 1.6 & 1.1 & 1.35 & -0.42 & 0.08 & -0.17 & 14.4 \\
\hline 1.68 & 1.8 & 1.3 & 1.55 & -0.12 & 0.38 & 0.13 & 7.73 \\
\hline 2.18 & 2.2 & 1.7 & 1.95 & -0.02 & 0.48 & 0.23 & 10.5 \\
\hline 2.68 & 2.6 & 1.9 & 2.25 & 0.08 & 0.78 & 0.43 & 16.04 \\
\hline
\end{tabular}




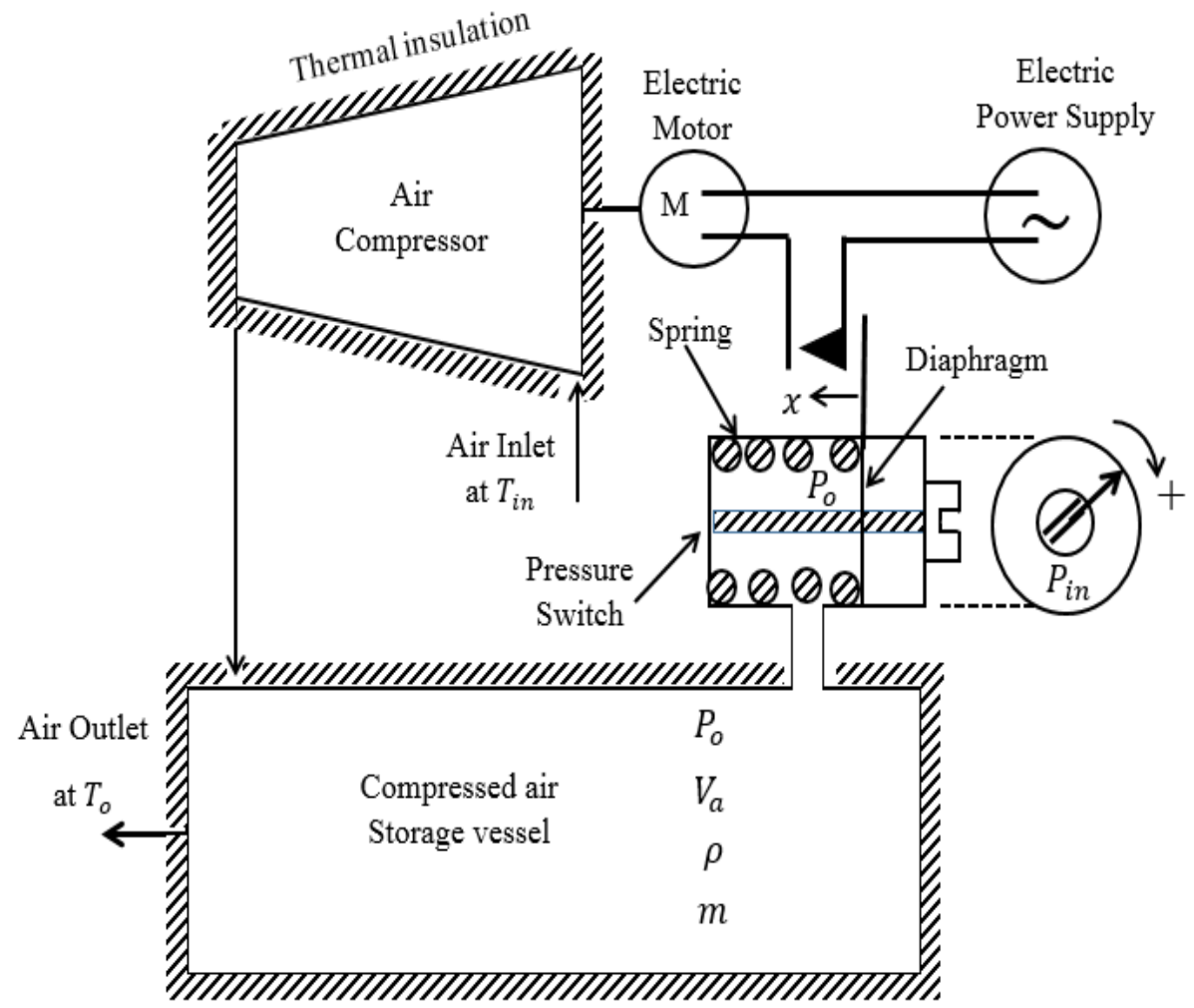

Thermal insulation

Fig. 1: Mathematical model

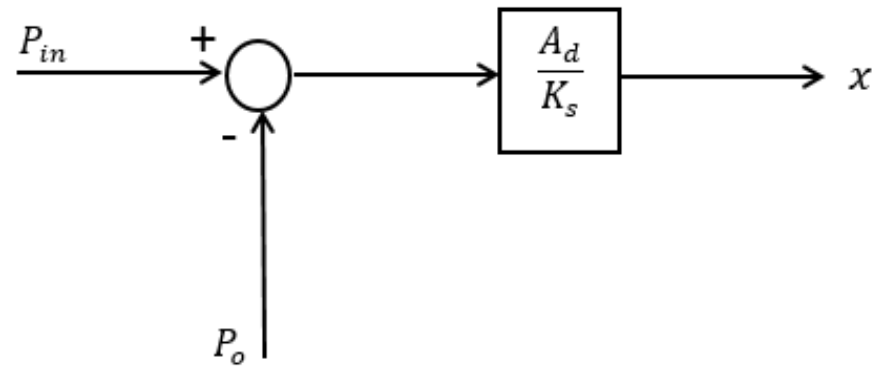

Fig. 2: Block diagram of the comparator

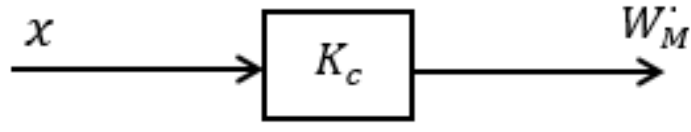

Fig. 3: Block diagram of the amplifier

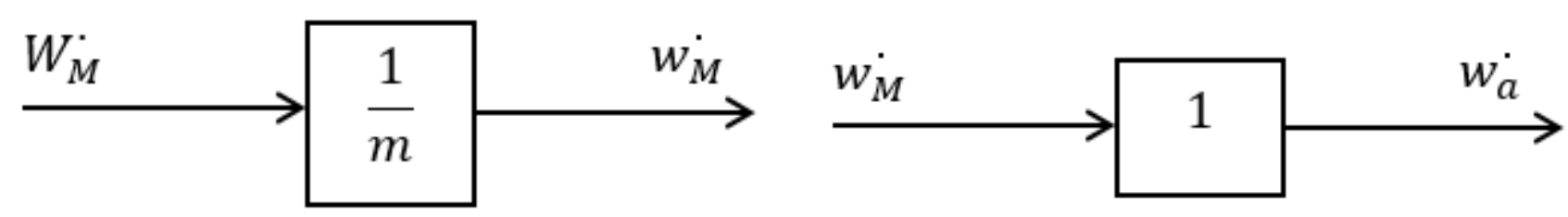

Fig. 4: Block diagram of the hydraulic process - motor

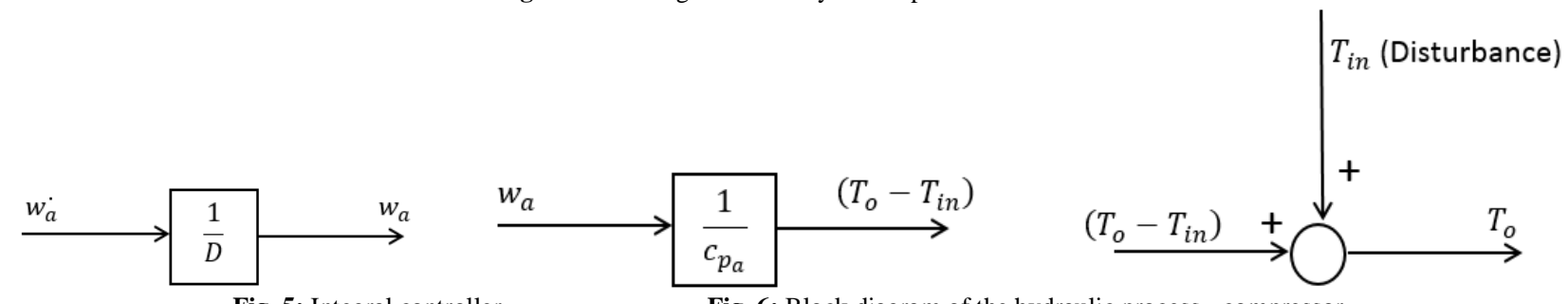

Fig. 5: Integral controller

Fig. 6: Block diagram of the hydraulic process - compressor

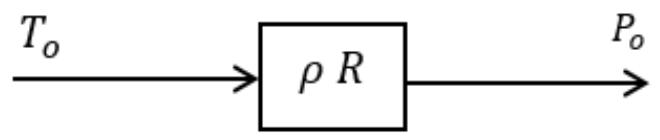

Fig. 7 Transfer function of the perfect gas law 


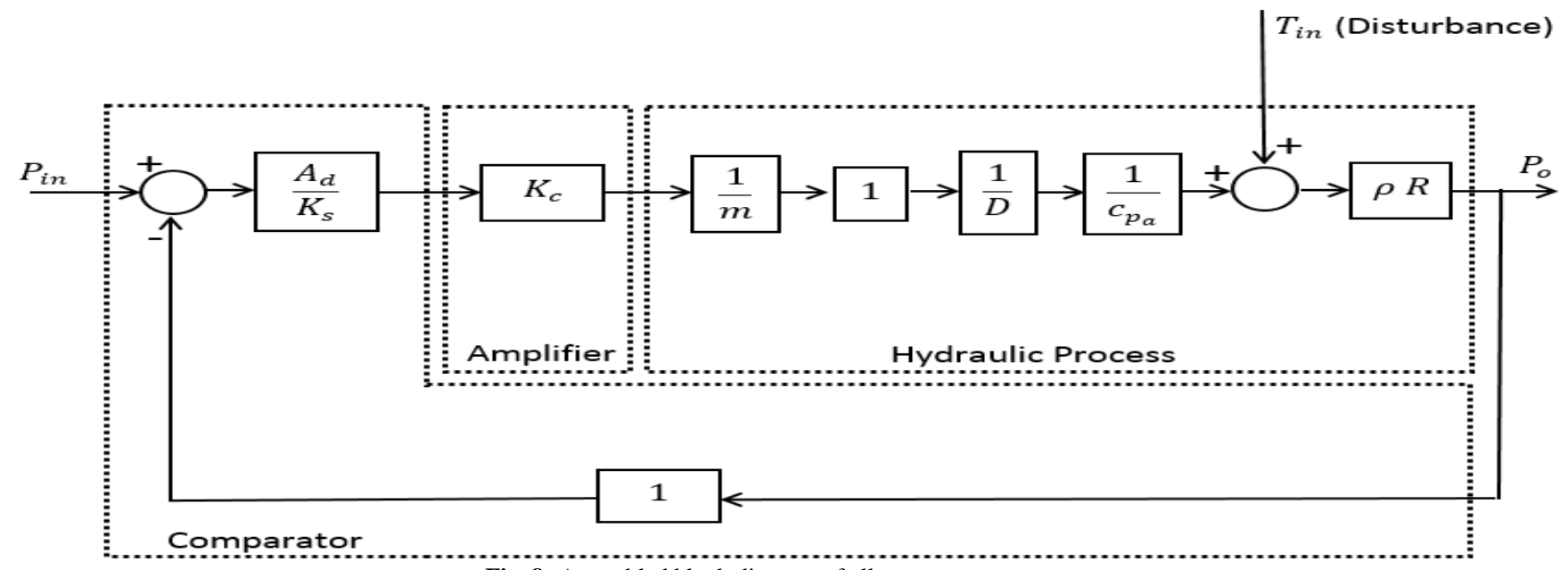

Fig. 8: Assembled block diagram of all process components

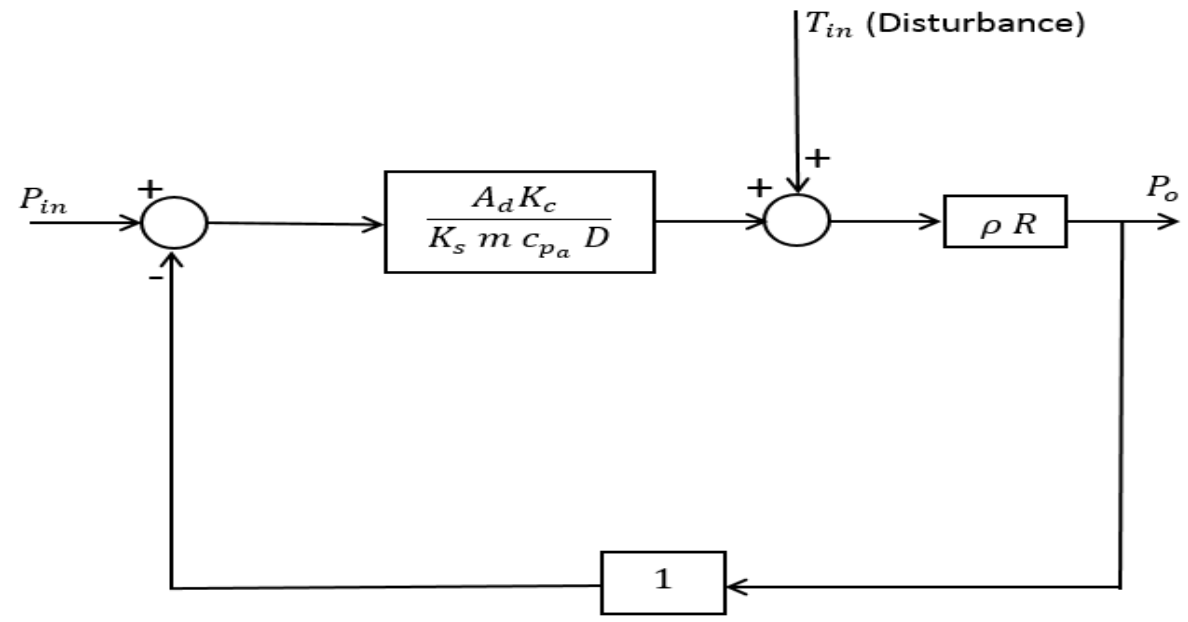

Fig. 9: Reduced block diagram of the pressure integral control system

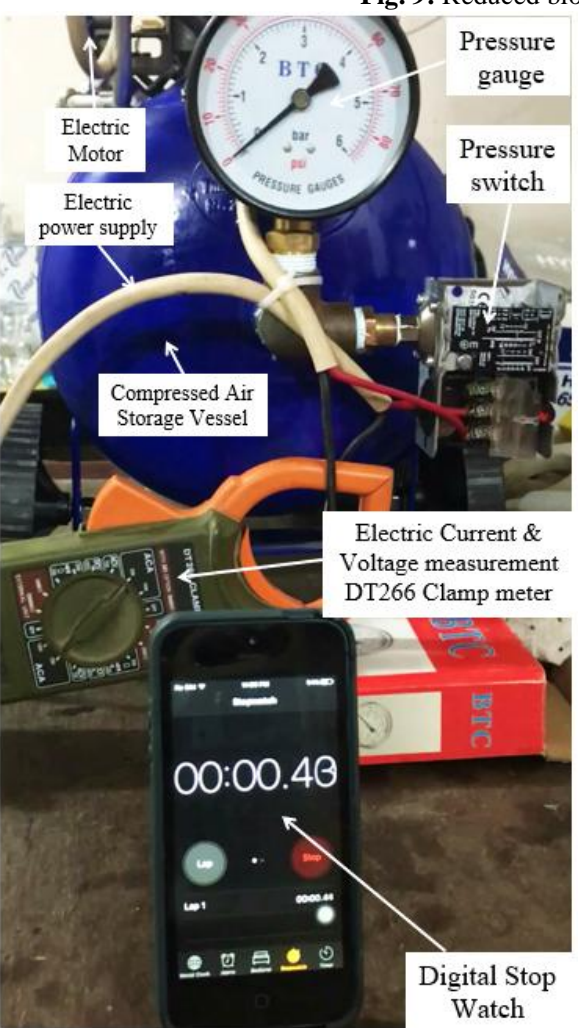

(a) Photo
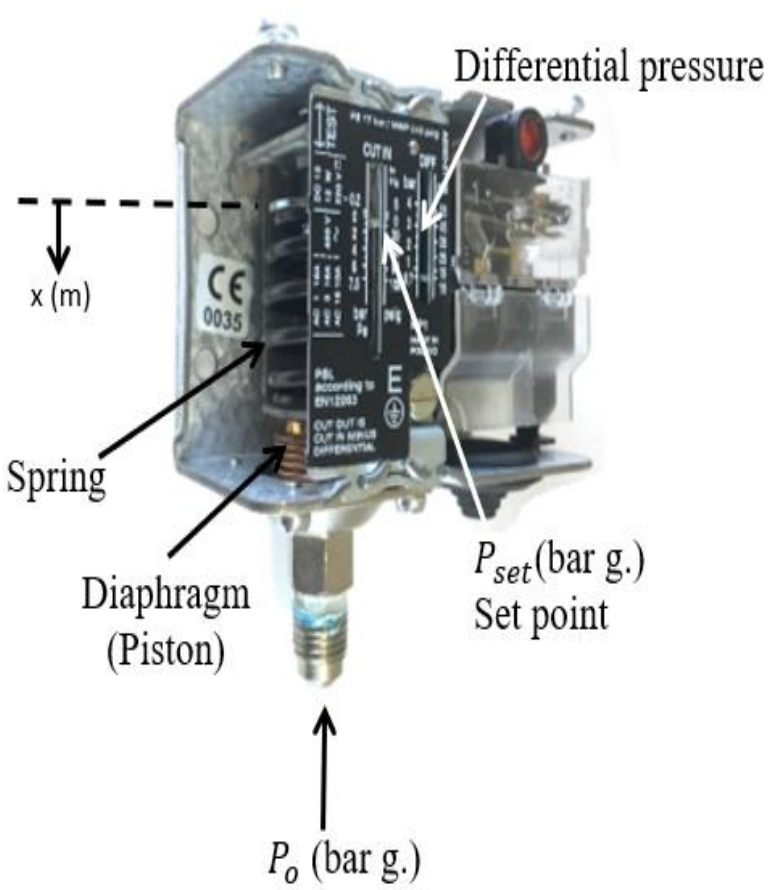

(b) Pressure switch

Fig. 10: Test rig 


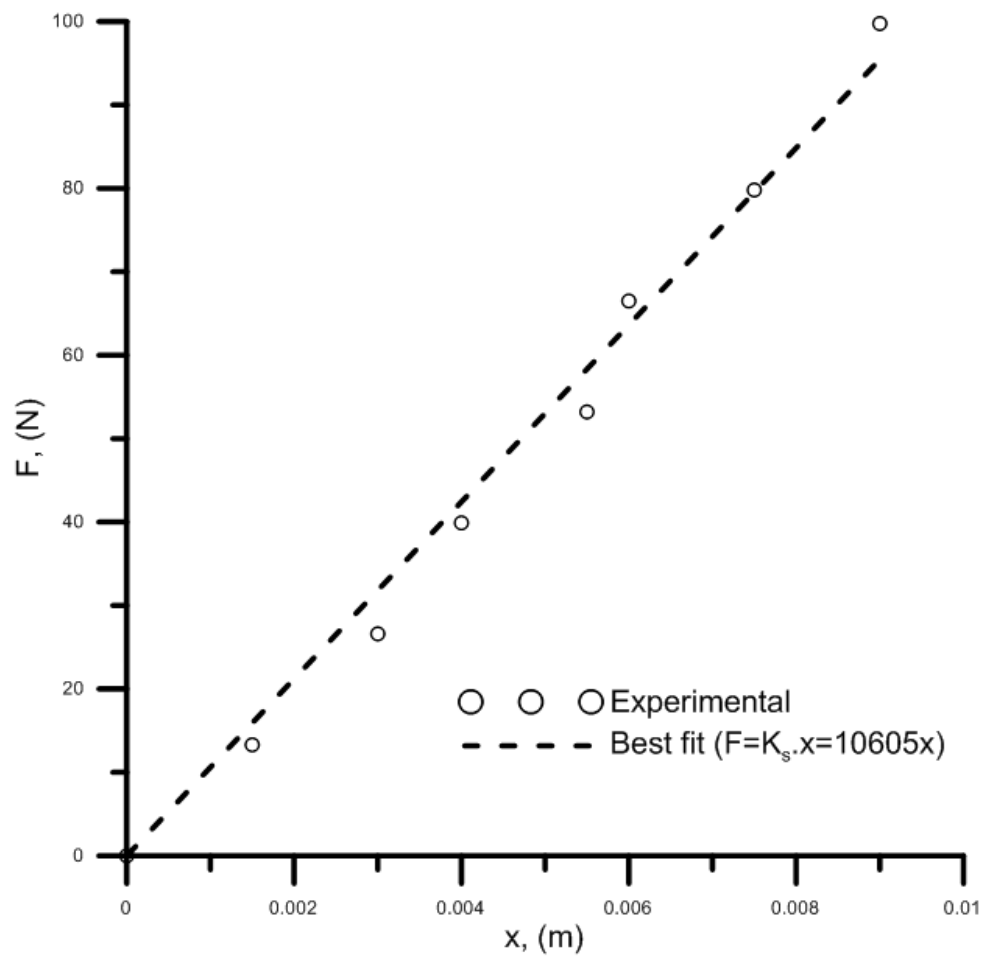

Fig. 11: Estimation of spring constant.

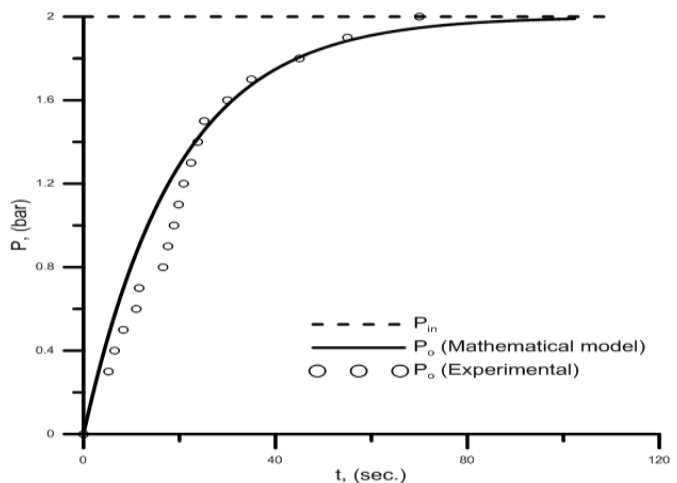

(a)

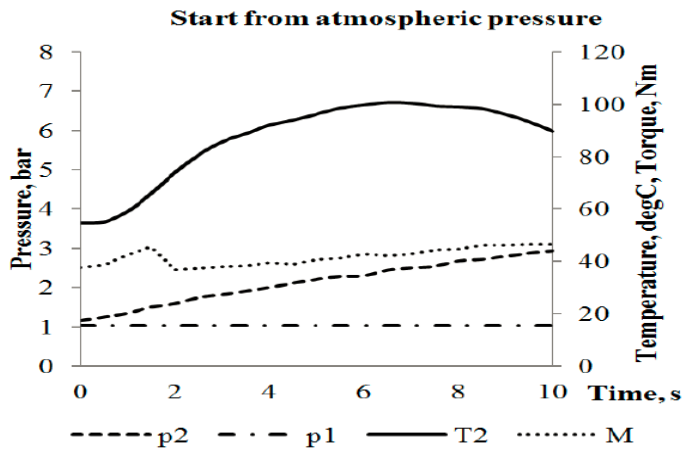

(b) (Chukanova et. al., 2013)

$\mathrm{P} 1=$ Inlet pressure

$\mathrm{P} 2=$ outlet pressure

$\mathrm{T} 2=$ outlet temperature

$\mathrm{M}=$ Compressor Torque

Fig. 12: Validation of the predicted results.

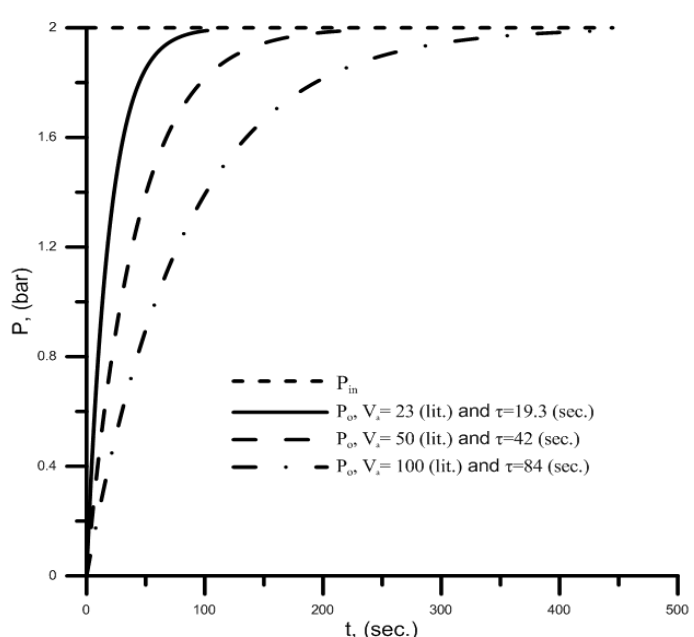

(a)

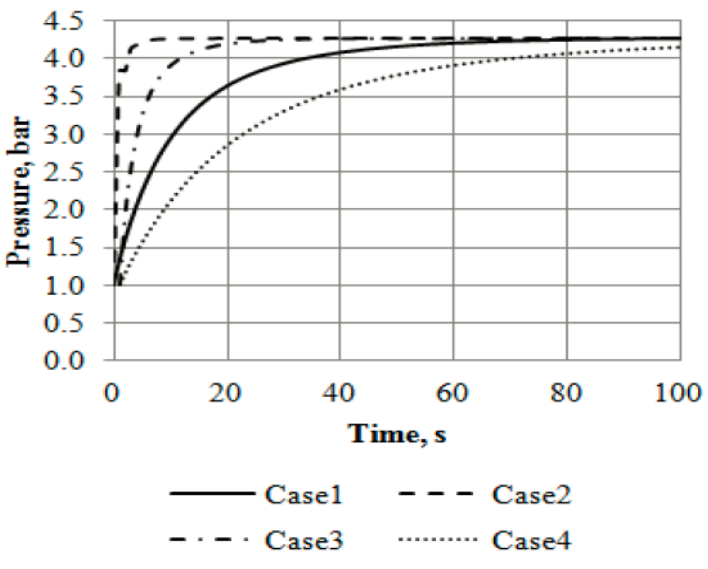

(b) (Chukanova et. al., 2013)

Case 1: $\mathrm{V}_{\mathrm{a}}=300$ litter

Case 2: $\mathrm{V}_{\mathrm{a}}=30$ litter

Case 3: $\mathrm{V}_{\mathrm{a}}=100$ litter

Case 4: $\mathrm{V}_{\mathrm{a}}=600$ litter

Fig. 13: Air compressor pressure response (with no disturbance signal) for different values of the compressed air storage vessel volume. 


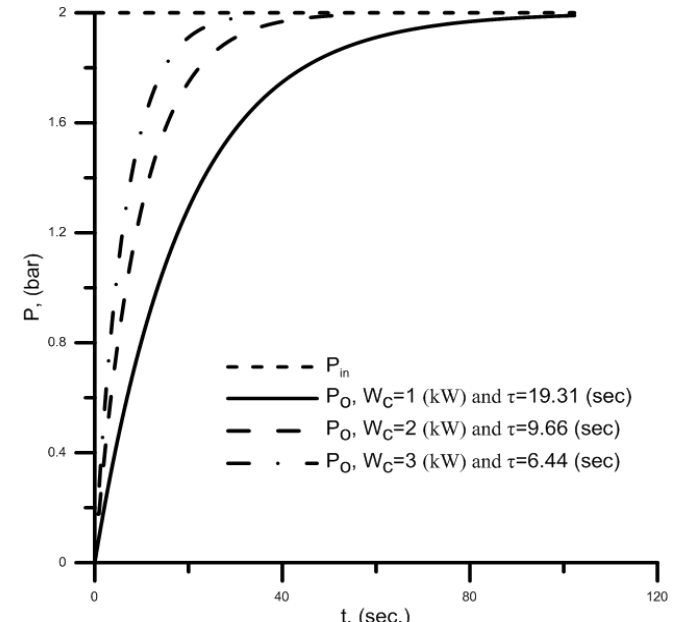

Fig. 14: Air compressor pressure response (with no disturbance signal) for different values of rated power of electric motor.

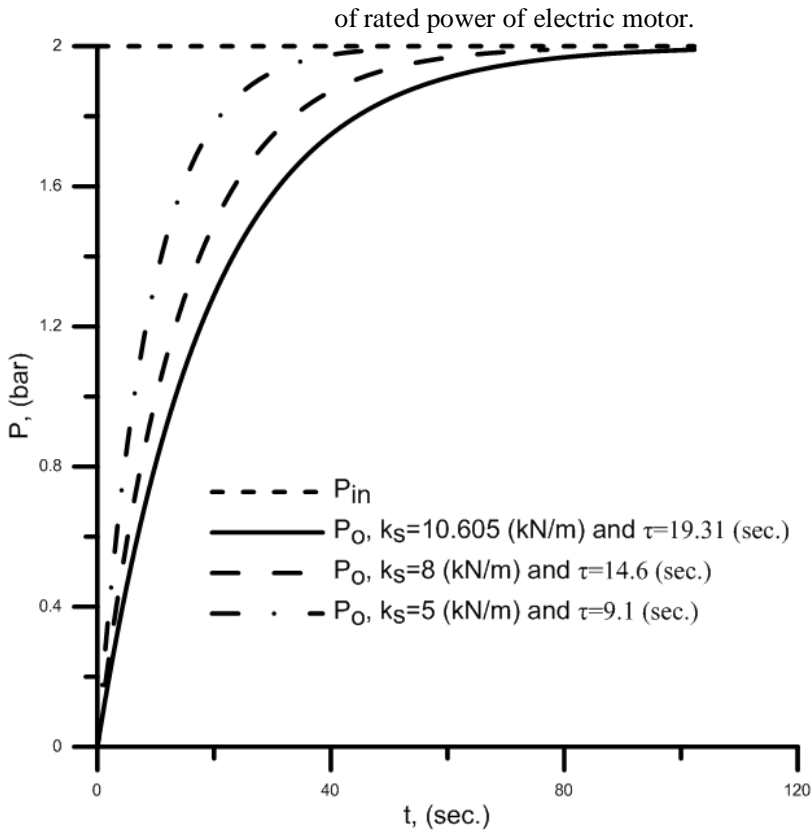

Fig. 16: Air compressor pressure response (with no disturbance signal)

for different values of spring constant.

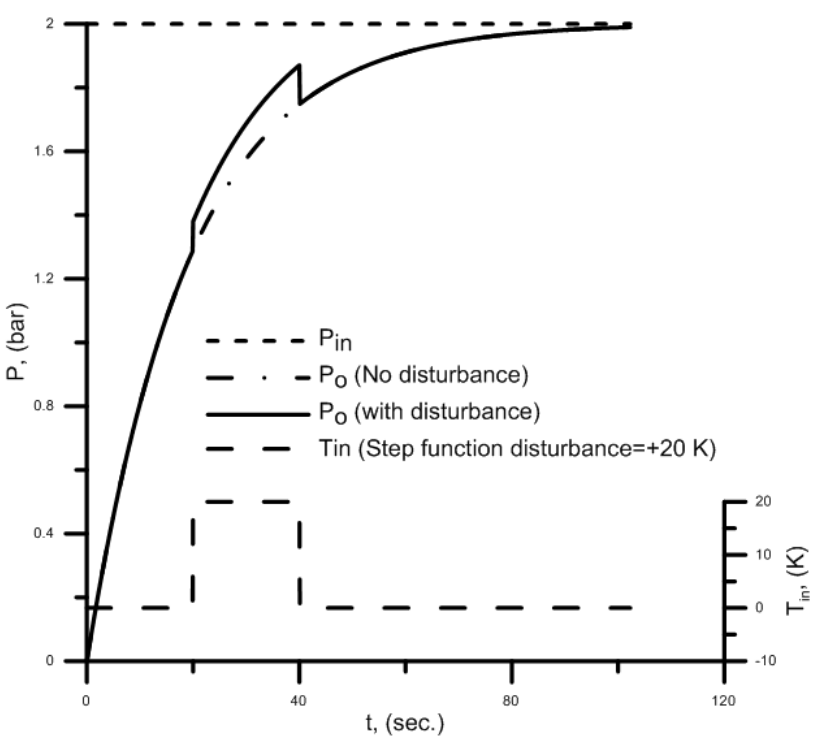

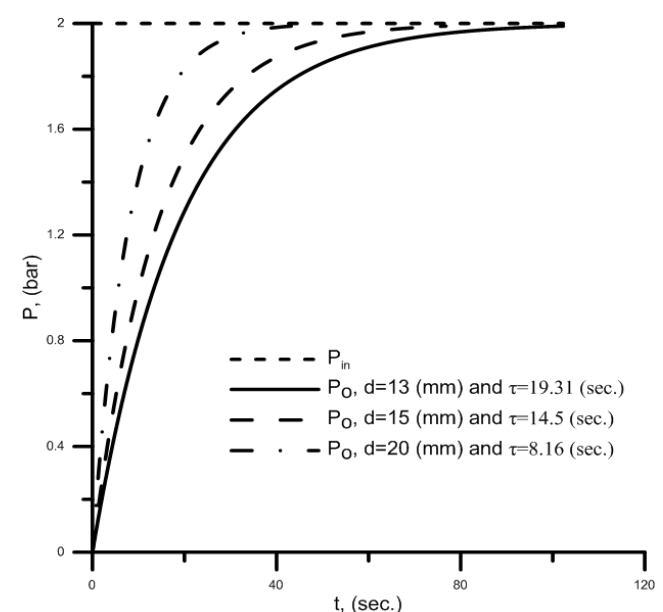

Fig. 15: Air compressor pressure response (with no disturbance signal) for different values of diaphragm diameter.

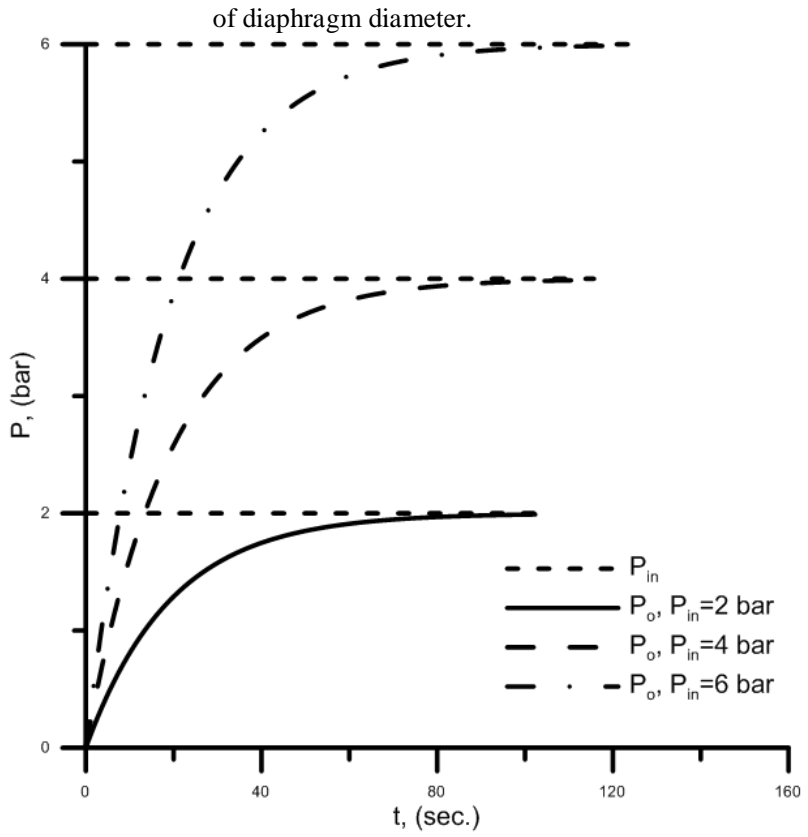

Fig. 17: Air compressor pressure response (with no disturbance signal) for different values of input pressure signal.

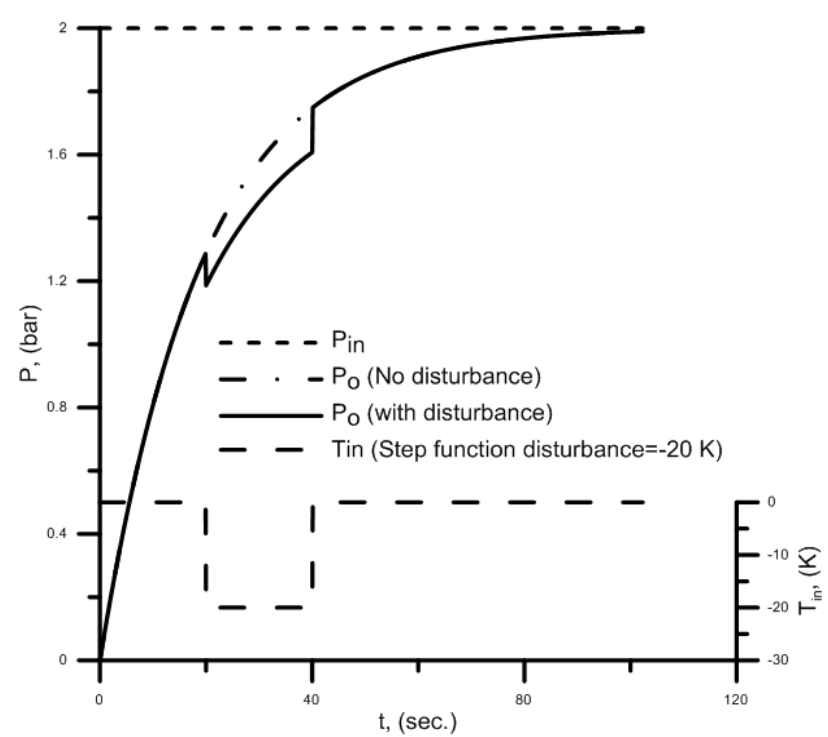

(b) 


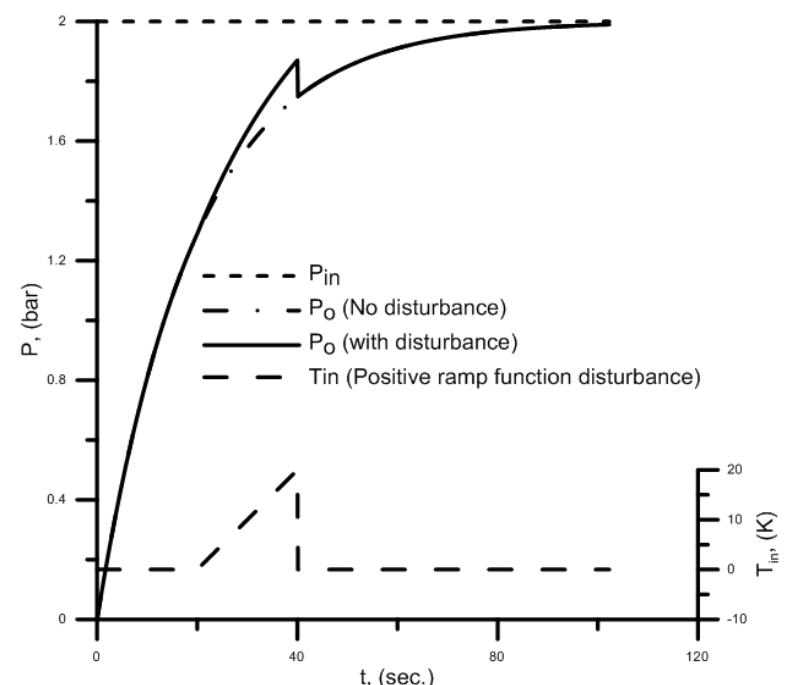

(c)

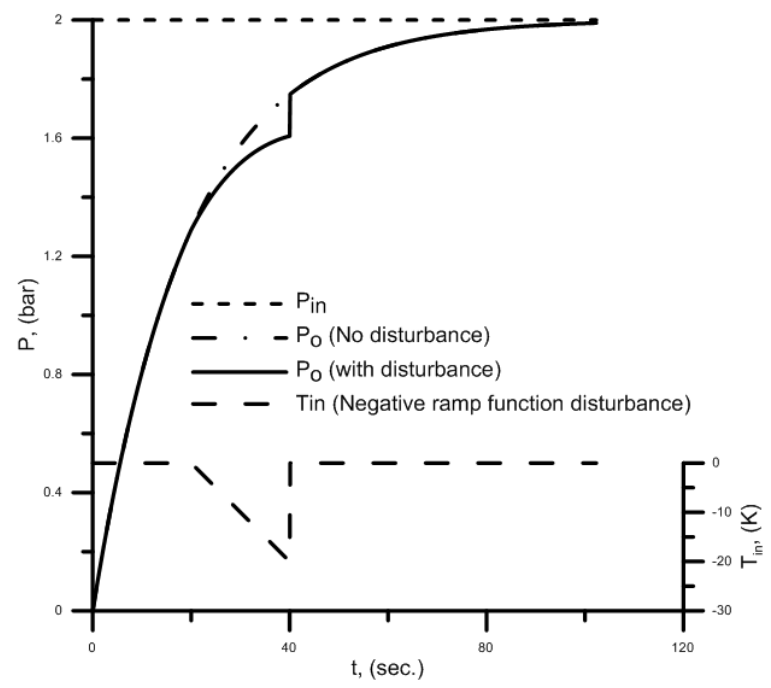

(d)

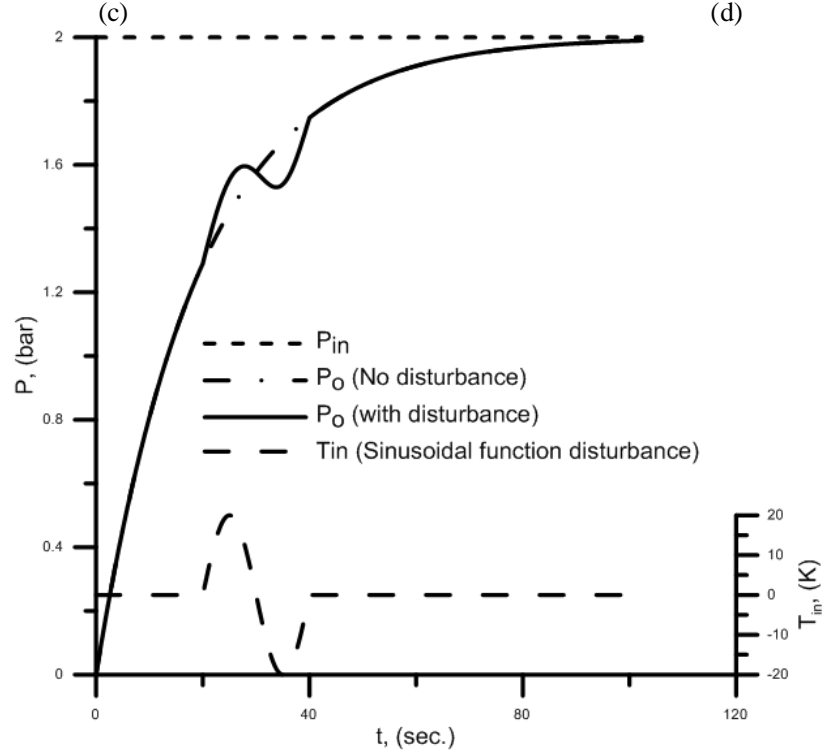

(e)

Fig. 18: Air compressor pressure response with different types of positive and negative functions of disturbance signals (step, ramp and sinusoidal functions).

(a) Positive step function disturbance signal, $T_{\text {in }}=+20 \mathrm{~K}$, at $(20 \mathrm{sec} . \leq t \leq 40 \mathrm{sec}$. $)$

(b) Negative step function disturbance signal, $T_{i n}=-20 \mathrm{~K}$, at $(20 \mathrm{sec} . \leq t \leq 40 \mathrm{sec}$. $)$

(c) Positive ramp function disturbance signal, $T_{\text {in }}=+1.0(t-20)$, at $(20 \mathrm{sec} . \leq t \leq 40 \mathrm{sec}$. $)$

(d) Negative ramp function disturbance signal, $T_{i n}=-1.0(t-20)$, at $(20 \mathrm{sec} . \leq t \leq 40 \mathrm{sec}$. $)$

(e) Sinusoidal function disturbance signal, $T_{\text {in }}=20 \mathrm{Sin}\left[\frac{2 \pi(t-20)}{20}\right]$, at $(20 \mathrm{sec} . \leq t \leq 40 \mathrm{sec}$. $)$ 